\title{
Thickness Control of Biomimetic Silica Thin Films: Grafting Density of Poly(2-(dimethylamino)ethyl methacrylate) Templates ${ }^{\dagger}$
}

\author{
Sung Ho Yang and Insung S. Choi* \\ Molecular-Level Interface Research Center \\ Department of Chemistry, KAIST, Daejeon 305-701, Korea.*E-mail: ischoi@kaist.ac.kr \\ Received October 27, 2009, Accepted February 11, 2010
}

Key Words: Biomimicry, Grafting density, Mixed self-assembled monolayers, Silica, Silicification

The nanometer-scaled control of silica thin films is one of the direct routes to the realization of various applications, including biomedicine, ${ }^{1}$ biosensors, ${ }^{2}$ heterogeneous catalysis, ${ }^{3}$ cell culture, ${ }^{4}$ and wettability. ${ }^{5}$ In the past decade, biomimetic silica synthesis has been investigated as a potential method for cost-effective and low-energy fabrication of silica films. While conventional fabrication methods involve harsh conditions, such as high temperature, extreme $\mathrm{pH}$, and presence of caustic reagents, biomimetic methods - utilizing peptides/proteins found in nature or synthetic polymers as catalytic templates - are considered advantageous for facilely generating and controlling silica thin films under physiologically mild conditions (at near neutral $\mathrm{pH}$ and room temperature). ${ }^{6}$ As initial attempts to fabricate silica films biomimetically, catalytic templates, either natural or synthetic, were introduced onto substrate surfaces by simple physisorption ${ }^{7}$ and layer-by-layer (LbL) deposition. Ball et al. produced silica/polyamine composite films by alternately depositing positively charged poly(diallyldimethylammonium chloride) (PDADMA) and negatively charged silicic acid that was a silicification precursor. ${ }^{8}$ We also demonstrated the formation of silica thin films ${ }^{9}$ and micropatterns ${ }^{10}$ by the LbL deposition of PDADMA and sodium polystyrene sulfonate, and subsequent biomimetic silicification. In addition, these biocompatible processes have been applied to encapsulate individual living cells with a silica shell. ${ }^{11}$ On the other hand, covalently bonded catalytic templates were introduced onto surfaces by grafting of polymers. For example, Wu et al. synthesized silica films on the end-tethered poly(L-lysine), which was formed by surface-initiated, vapor deposition polymerization. ${ }^{12}$ We have shown that the films of poly(2-(dimethylamino)ethyl methacrylate) (PDMAEMA) ${ }^{13}$ and quaternized PDMAEMA (q-PDMAEMA $)^{5,14}$ - formed by surface-initiated, atom transfer radical polymerization (SI-ATRP) - acted as catalytic templates for biomimetic polycondensation of silicic acid derivatives and others. ${ }^{15}$

In our previous reports, we demonstrated several approaches to nanometer-scaled control of the thickness and surface-morphologies of silica thin films, including deposition number of polymeric multilayers in the LbL processes, ${ }^{9,10}$ polymerization conditions of PDMAEMA films (monomer concentration and reaction time), ${ }^{13 a}$ and counteranions of q-PDMAEMA films. ${ }^{5,14}$ Herein, we suggest another approach to the control of the thick-

${ }^{\dagger}$ This paper is dedicated to Professor Sunggak Kim on the occasion of his honorable retirement. ness (and surface-morphologies) of silica films: grafting density of PDMAEMA films. Our rationale is as follows. The selfassembly (or aggregation) of positively charged polymers (e.g., amine-containing polymers; polyamines) is reported to be a pre-requisite for the biomimetic silicification in solution. ${ }^{16}$ Highdensity PDMAEMA films, therefore, could act as a catalytic template with their stretched conformation as shown in our previous studies, while low-density PDMAEMA films should have a collapsed structure to form the aggregate. The degree of the chain collapse during the biomimetic silicification, determining the thickness of silica films, would be varied by the grafting density of PDMAEMA films, given PDMAEMA chain length.

The grafting density of the PDMAEMA films was controlled by the surface density of the polymerization initiator. We prepared gold substrates presenting mixed self-assembled monolayers (SAMs) of the initiator $\left(\left(\mathrm{BrC}\left(\mathrm{CH}_{3}\right)_{2} \mathrm{COO}\left(\mathrm{CH}_{2}\right)_{11} \mathrm{~S}\right)_{2}\right)^{17}$ and dodecanethiol with various ratios. The PDMAEMA films were then formed from the mixed SAM-coated surfaces by SI-ATRP of DMAEMA. The mixed SAM-coated gold substrates $\left(1 \times 1.5 \mathrm{~cm}^{2}\right)$ were placed in an argon-purged Erlenmeyer flask, and to the flask was added a mixture of $\mathrm{CuBr}(0.9 \mathrm{mmol})$, 2,2'-dipyridyl (1.8 mmol), DMAEMA (90 mmol), and degassed water $(90 \mathrm{~mL})$. After $4 \mathrm{~h}$ at room temperature, the resulting sub-

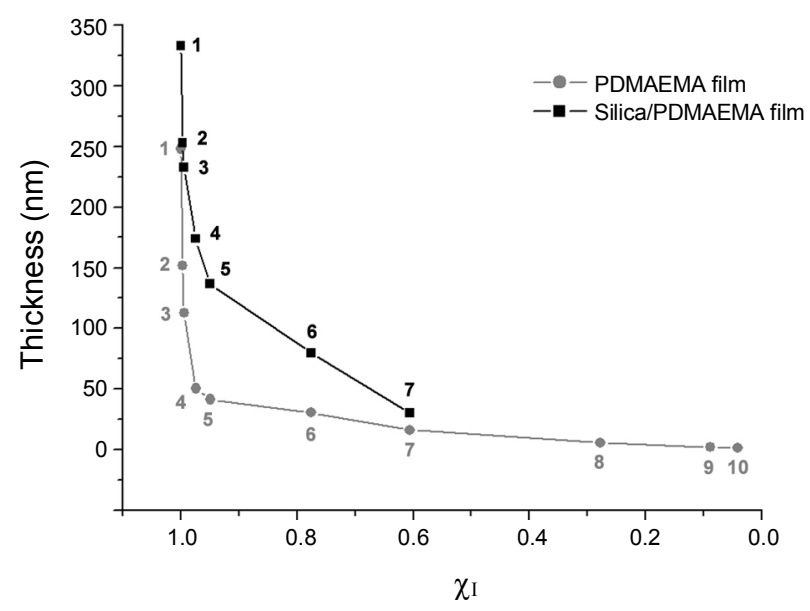

Figure 1. Thickness of PDMAEMA and silica/PDMAEMA films vs. mole fraction of the initiator in solution. Mole fraction $\left(\chi_{\mathrm{I}}\right)$ : 1 (Sample 1), 0.997 (Sample 2), 0.995 (Sample 3), 0.974 (Sample 4), 0.950 (Sample 5), 0.776 (Sample 6), 0.601 (Sample 7), 0.278 (Sample 8), 0.088 (Sample 9), and 0.041 (Sample 10). The number, N, indicates Sample N. 

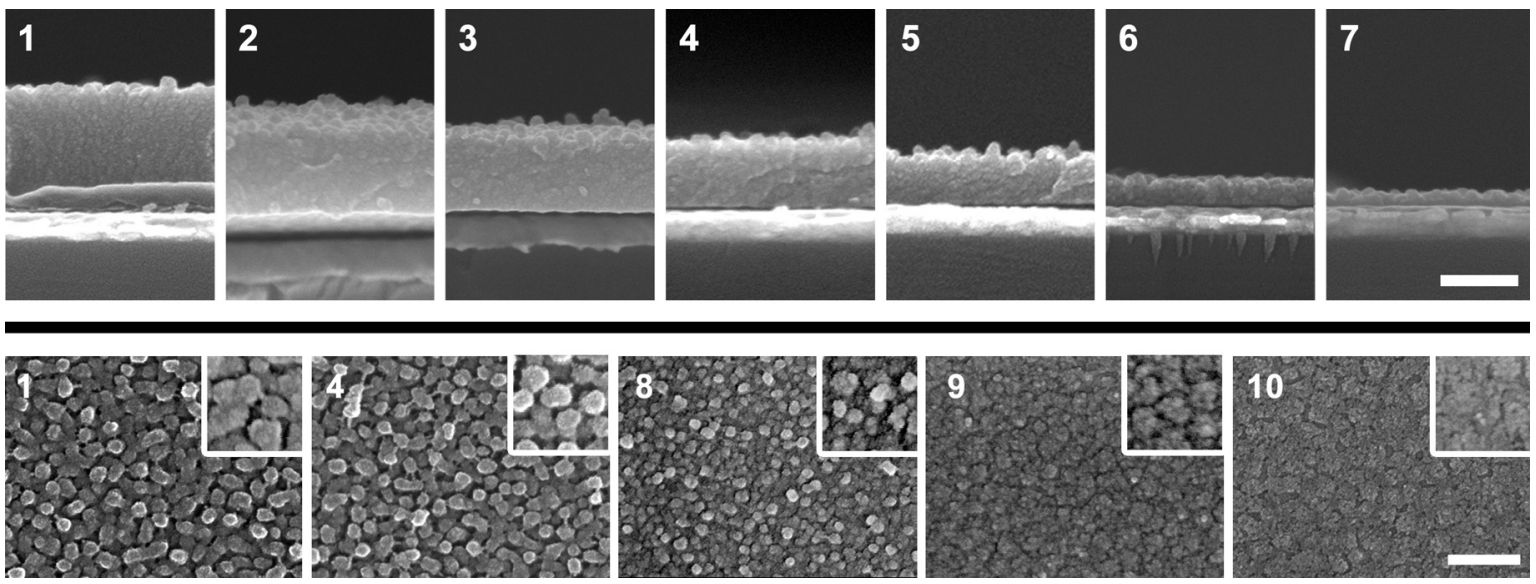

Figure 2. SEM micrographs of the silica/PDMAEMA films. (Top) Cross-sectional views and (Bottom) top views. Insets are magnified views. The scale bar is $200 \mathrm{~nm}$.

strates were taken out, and rinsed with water and ethanol several times. After formation of the PDMAEMA films, the substrates were placed for $60 \mathrm{~min}$ in the $50-\mathrm{mM}$ silicic acid solution that had been made by adding $0.1 \mathrm{mM} \mathrm{HCl}$ solution of tetramethyl orthosilicate (100 mM) to $100 \mathrm{mM}$ phosphate buffer ( $\mathrm{pH} 5.5)$ with 1:1 (v/v) ratio. The formation of PDMAEMA and silica films was confirmed by FT-IR and X-ray photoelectron spectroscopy. ${ }^{13,14}$

We prepared ten different samples of PDMAEMA films with different mole fractions of the initiator in the thiol solutions of the initiator and dodecanethiol, and measured the thickness of the films by ellipsometry (Figure 1). All ten samples were made under the same polymerization conditions. The mole fractions of the initiator $\left(\chi_{\mathrm{I}}\right)$ were varied from 1 (Sample 1) to 0.041 (Sample 10). The ellipsometric thickness of the films decreased as $\chi_{\mathrm{I}}$ (in other words, surface density of the initiator) decreased, which indicated that the grafting density of the PDMAEMA films was differentiated by the surface density of the initiator. The thickness decrease was found to be much greater with small amounts of dodecanethiol (from Sample 1 to Sample 5) than that with higher mole fractions of dodecanethiol (from Sample 6 to Sample 10): for example, the 5\% presence of dodecanethiol in solution $\left(\chi_{\mathrm{I}}=0.95\right.$; Sample 5) decreased the thickness by $83 \%$ (from 248.3 to $41.4 \mathrm{~nm}$ ). We believe that the observed effect of dodecanethiol could be explained by difference in relative stability of SAMs. ${ }^{18}$ Dodecanethiol has only alkyl groups in the chain, but the initiator does the bulky 2bromo-2-methyl propionyl group at the end of the chain. The well-packed SAMs of dodecanethiol would be formed more stably and densely on gold than the initiator, and thus, the actual surface density of the initiator be lower than the value of $\chi_{\mathrm{I}}$.

The information on the thicknesses of the resulting silica/ PDMAEMA films was obtained from the cross-sectional views of scanning electron microscopy (SEM) micrographs (Figure 1 and top images in Figure 2). The films of Samples 8-10 were too thin and irregular to measure the thickness. After silicification, the silica/PDMAEMA films became thicker, as expected from the previous reports. ${ }^{10,14}$ The thickness was found to be related directly with the ellipsometric thickness (i.e., the grafting density) of the PDMAEMA films: the thickness of the silica/
PDMAEMA films increased, as that of the PDMAEMA films increased. The surface morphology of the silica/PDMAEMA films was also characterized by SEM (bottom images in Figure 2). The morphologies of silica were changed from compactly packed large silica particulates to loosely packed small silica particulates. Such transition was observed to occur for Sample $8\left(\chi_{\mathrm{I}}=0.278\right)$. As mentioned before, biomimetic polycondensation of oligomeric silicic acid derivatives is thought to be directed by the predetermined template of aggregated polyamines. For example, Sumper et al. reported that the aggregation was achieved by electrostatic interactions between cationic polyamines and polyvalent anions in solution: bigger templates, formed by stronger electrostatic interactions, resulted in bigger silica particles, but no silica particle precipitated in the absence of polyvalent anions. ${ }^{16}$ In contrast, we showed that the PDMAEMA films functioned in a different manner from solutionbased templates at the silicification process: because densely grafted PDMAEMA films were inherently aggregated templates, monovalent anions were also effective in inducing and controlling silica structures. ${ }^{14}$ Taken together, the previous reports imply that the structures of biomimetic silica films could be controlled by the grafting density that determines the degree of aggregation of polymeric chains at surfaces for the silicification. In the case of high-density initiators, the PDMAEMA chains were stretched away from the surface to avoid steric congestion between the chains within short distance, which resulted in thick, high-density PDMAEMA films (Figure 3a). ${ }^{19}$ In the case of low-density initiators, the polymeric chains were coagulated by themselves and formed mushroom-like structures, which resulted in low-dense and thin PDMAEMA films (Figure $3 b$ ). As a result, the structure of catalytic templates dictated the structure of silica films: the high-density PDMAEMA films (more aggregated templates) led to the formation of thick silica films composed of large silica particulates (Figure 3c), but low-density of PDMAEMA films (less aggregated templates) yielded thin silica films composed of small silica particulates (Figure 3d).

In summary, we demonstrated that the thickness (and surface-morphology) of biomimetic silica films could be controlled by varying the grafting density of catalytic templates. We 
(a)

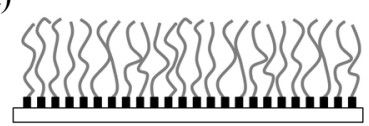

(c)

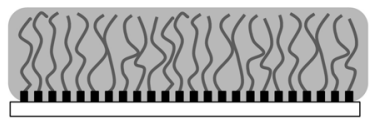

(b)

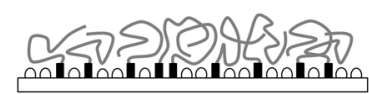

(d)

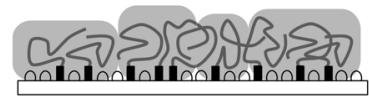

Figure 3. Schematic representation of (a) high-density PDMAEMA films, (b) low-density PDMAEMA films, (c) high-density silica/PDMAEMA films, and (d) low-density silica/PDMAEMA films. Highdensity PDMAEMA films generated thick silica films composed of large silica particulates, while low-density PDMAEMA films did thin silica films composed of small silica particulates.

believe that the thickness control resulted from the required aggregation of PDMAEMA chains. Of interest, we did observe the silica formation for Sample $10\left(\chi_{\mathrm{I}}=0.041\right)$, although the silica film was extremely thin. This result implied that a PDMAEMA chain was long enough to make a complex with other PDMAEMA chains (and silicic acid derivatives), or a single PDMAEMA chain was catalytically active for silicification. We expect that further research on the grafting density of PDMAMEA films would be beneficial in gaining a deeper insight into biomimetic silicification as well as in controlling silica thin films. The detailed studies will be our next research thrust.

\section{Experimental Section}

Materials. Gold-coated silicon wafers (with a titanium adhesion layer of $5 \mathrm{~nm}$ and thermally evaporated gold layer of 100 nm, K-MAC, Korea), dodecanethiol (DDT, 99\%, Aldrich), 2-(dimethylamino)ethyl methacrylate (DMAEMA, 98\%, SigmaAldrich), copper(I) bromide (CuBr, 99.999\%, Sigma-Aldrich), 2,2'-dipyridyl ( $\geq 99 \%$, Sigma-Aldrich), tetramethyl orthosilicate (TMOS, 99\%, Aldrich), sodium phosphate dibasic (99\%, Aldrich), sodium dihydrogen phosphate (99\%, Aldrich), aluminum oxide $\left(\mathrm{Al}_{2} \mathrm{O}_{3}\right.$, activated, basic, Brockmann I, standard grade, 150 mesh, Sigma-Aldrich), absolute ethanol (99.8\%, Merck) were used as received. Ultrapure water $(18.3 \mathrm{M} \Omega \cdot \mathrm{cm})$ from the Human Ultrapure System (Human Corp., Korea) was used. The polymerization initiator, $\left(\mathrm{BrC}\left(\mathrm{CH}_{3}\right)_{2} \mathrm{COO}\left(\mathrm{CH}_{2}\right)_{11} \mathrm{~S}\right)_{2}$, was synthesized by following the reported procedure. ${ }^{17}$

Synthetic procedures. The gold substrate was immersed for $12 \mathrm{~h}$ in an ethanolic solution $(10 \mathrm{mM})$ of dodecanethiol and the initiator $\left(\mathrm{BrC}\left(\mathrm{CH}_{3}\right)_{2} \mathrm{COO}\left(\mathrm{CH}_{2}\right)_{11} \mathrm{~S}\right)_{2}$ with various ratios for forming mixed self-assembled monolayers (SAMs) on gold. Before performing surface-initiated, atom transfer radical polymerization (SI-ATRP) of DMAEMA, DMAEMA was purified by column chromatography on basic aluminum oxide, and water was degassed and purged with argon. All the polymerization steps were carried out under argon atmosphere. The mixed SAM-coated gold substrates $\left(1 \times 1.5 \mathrm{~cm}^{2}\right)$ were placed in an argon-purged Erlenmeyer flask, and to the flask was added a mixture of $\mathrm{CuBr}$ (0.9 mmol), 2,2'-dipyridyl (1.8 mmol), DMAEMA $(90 \mathrm{mmol})$, and degassed water $(90 \mathrm{~mL})$. After $4 \mathrm{~h}$ at

room temperature, the resulting substrates were taken out, and rinsed with water and ethanol several times. The formation of the PDMAEMA film was confirmed by the previously reported method. ${ }^{14,15}$ Briefly, the IR spectrum of PDMAEMA showed peaks at $1732\left(\mathrm{C}=\mathrm{O}\right.$ stretching), $1461\left(-\mathrm{CH}_{2}\right.$ - bending $)$, and 1155 $\mathrm{cm}^{-1}$ (C-N stretching). After formation of the PDMAEMA films, the substrates were placed for $60 \mathrm{~min}$ in the $50-\mathrm{mM}$ silicic acid solution that had been made by adding $0.1-\mathrm{mM} \mathrm{HCl}$ solution of tetramethyl orthosilicate $(100 \mathrm{mM})$ to $100-\mathrm{mM}$ phosphate buffer ( $\mathrm{pH} 5.5)$ with 1:1 (v/v) ratio. The formation of silica films was also confirmed by FT-IR. The silica/PDMAEMA films showed IR peaks at 1228 ( $\mathrm{Si}$-O-Si asymmetric stretching), 963 ( $\mathrm{Si}-\mathrm{O}^{-}$stretching), and $802 \mathrm{~cm}^{-1}$ (Si-O-Si symmetric stretching), which indicated the successful formation of silica films.

Characterizations. IR spectra were recorded on a Thermo Nicolet Nexus FT-IR spectrometer in a SAGA mode. Fieldemission scanning electron microscopy (FE-SEM) images were obtained by using an FEI XL FEG/SFEG microscope (FEI Co., Netherlands) equipped with EDX module, at an accelerating voltage of $10 \mathrm{eV}$. All samples were sputter-coated with platinum. The film thickness was measured with a Gaertner L116s ellipsometer (Gaertner Scientific Corporation, USA) equipped with a He-Ne laser $(632.8 \mathrm{~nm})$ at a $70^{\circ}$ angle of incidence. A refractive index of 1.46 was used for all the films.

Acknowledgments. This work was supported by the Korea Research Foundation Grant funded by the Korean Government (MOEHRD, KRF-2008-313-C00496) and the Basic Science Research Program through the National Research Foundation of Korea (NRF) funded by the Ministry of Education, Science and Technology (2009-0083525). We also thank M. S. Hyun and M. H. Kim at the National Nanofab Center for the SEM analysis.

\section{References}

1. (a) Izquierdo-Barba, I.; Vallet-Regí, M.; Kupferschmidt, N.; Terasaki, O.; Schmidtchen, A.; Malmsten, M. Biomaterials 2009, 30, 5729. (b) Segal, E.; Perelman, L. A.; Cunin, F.; Di Renzo, F.; Devoisselle, J. M.; Li, Y. Y.; Sailor, M. J. Adv. Funct. Mater. 2007, 17,1153 .

2. (a) Pierce, A. L.; Sommakia, S.; Rickus, J. L.; Otto, K. J. J. Neurosci. Meth. 2009, 180, 106. (b) Tu, Y. F.; Di, J. W.; Chen, X. J. J. Sol-Gel Sci. Technol. 2005, 33, 187. (c) Li, T.; Yao, Z.; Ding, L. Sensor. Actuat. B 2004, 101, 155. (d) Kambhampati, D. K.; Jakob, T. A. M.; Robertson, J. W.; Cai, M.; Pemberton, J. E.; Knoll, W. Langmuir 2001, 17, 1169. (e) Miao, Y.; Tan, S. N. Anal. Chim. Acta 2001, 437, 87. (f) Wang, B.; Zhang, J.; Dong, S. Biosens. Bioelectron. 2000, 15, 397. (g) Li, J.; Chia, L. S.; Goh, N. K.; Tan, S. N. Anal. Chim. Acta 1998, 362, 203.

3. (a) Maheswara, M.; Oh, S. H.; Kim, K.; Do, J. Y. Bull. Korean Chem. Soc. 2008, 29, 1752. (b) Petrucci, M. G. L.; Kakkar, A. K. Chem. Mater. 1999, 11, 269.

4. Li, X.; Barua, S.; Rege, K.; Vogt, B. D. Langmuir 2008, 24, 11935.

5. Cho, W. K.; Kang, S. M.; Kim, D. J.; Yang, S. H.; Choi, I. S. Langmuir 2006, 22, 11208.

6. Brutchey, R. L.; Morse, D. E. Chem. Rev. 2008, 108, 4915.

7. (a) Helmecke, O.; Hirsch, A.; Behrens, P.; Menzel, H. J. Coll. Interface Sci. 2008, 321, 44. (b) Coffman, E. A.; Melechko, A. V.; Allison, D. P.; Simpson, M. L.; Doktycz, M. J. Langmuir 2004, 20, 8431. (c) Brott, L. L.; Naik, R. R.; Pikas, D. J.; Kirkpatrick, S. M.; Tomlin, D. W.; Whitlock, P. W.; Clarson, S. J.; Stone, M. O. 
Nature 2001, 413, 291.

8. Laugel, N.; Hemmerle, J.; Porcel, C.; Voegel, J.-C.; Schaaf, P.; Ball, V. Langmuir 2007, 23, 3706.

9. Yang, S. H.; Park, J. H.; Choi, I. S. Bull. Korean Chem. Soc. 2009, 30, 2165.

10. Yang, S. H.; Choi, I. S. Chem. Asian J. 2009, 4, 382.

11. Yang, S. H.; Lee, K.-B.; Kong. B.; Kim, J.-H.; Kim, H.-S.; Choi, I. S. Angew. Chem. Int. Ed. 2009, 48, 9160.

12. Wu, J.-C.; Wang, Y.; Chen, C.-C.; Chang, Y.-C. Chem. Mater. 2008, 20, 6148 .

13. (a) Kim, D. J.; Lee, K.-B.; Lee, T. G.; Shon, H. K.; Kim, W.-J.; Paik, H.-j.; Choi, I. S. Small 2005, 1, 992. (b) Kim, D. J.; Lee, K. B.; Chi, Y. S.; Kim, W. J.; Paik, H.-j.; Choi, I. S. Langmuir 2004, 20, 7904.

14. Yang, S. H.; Park, J. H.; Cho, W. K.; Lee, H.-S.; Choi, I. S. Small
2009, 5, 1947.

15. Yang, S. H.; Kang, K.; Choi, I. S. Chem. Asian J. 2008, 3, 2097.

16. (a) Sumper, M.; Kröger, N. J. Mater. Chem. 2004, 14, 2059. (b) Sumper, M.; Lerenz, S.; Brunner, E. Angew. Chem. Int. Ed. 2003, 42, 5192.

17. Shah, R. R.; Merreceyes, D.; Husemann, M.; Rees, I.; Abbott, N. L.; Hawker, C. J.; Hedrick, J. L. Macromolecules 2000, 33, 597.

18. (a) Min, H.; Jung, G.; Moon, D. W.; Choi, I. S.; Lee, T. G. Appl. Surf. Sci. 2008, 255, 1037. (b) Kong, B.; Kim, Y.; Choi, I. S. Bull. Korean Chem. Soc. 2008, 29, 1843. (c) Offord, D. A.; John, C. M.; Linford, M. R.; Griffin, J. H. Langmuir 1994, 10, 883. (d) Offord, D. A.; John, C. M.; Griffin, J. H. Langmuir 1994, 10, 761.

19. Advincula, R. C.; Brittain, W. J.; Caster, K. C.; Rühe, J. In Polymer Brushes: Synthesis, Characterization, Applications; Wiley-VCH: Weinheim, Germany, 2004. 